\title{
Inferência dos estados de ânimo do aluno em um ambiente virtual de aprendizagem baseada em redes bayesianas
}

\section{Student's moods inference in a virtual learning environment based on Bayesian networks}

\begin{abstract}
Resumo: Este artigo apresenta um mecanismo de inferência de estados de ânimo, tendo em vista dotar ambientes virtuais de aprendizagem (AVA) com uma ferramenta apta a reconhecer a motivação do aluno. O modelo de inferência tem como parâmetros os traços de personalidade obtidos através do Inventário Fatorial de Personalidade (IFP); os fatores motivacionais reconhecidos através dos padrões de comportamento; e a subjetividade afetiva identificada em textos disponibilizados nas funcionalidades de comunicação do AVA. Na máquina de inferência, tais variáveis são tratadas sob raciocínio probabilístico, mais precisamente por redes bayesianas.

Palavras-chave: Modelagem Afetiva. Redes Bayesianas. Ambientes Virtuais de Aprendizagem.

Abstract: This paper presents an inference engine of moods to provide virtual learning environments (VLE) with a framework able to recognize the student's motivation. The inference model considers the personality traits obtained from Inventário Fatorial de Personalidade (IFP), a Brazilian peravion behavioral patterns, and text subjectivity available in the corian networks to process such variables in a probabilistic reasoning.

Keywords: Affective Modeling. Bayesian Networks. Virtual Learning Environments.
\end{abstract}

LONGHI, Magalí Teresinha; BEHAR, Patricia Alejandra; BERCHT', Magda. Inferência dos eśtados de ânimo do aluno em um ambiente virtual de aprendizagem baseada em redes bayesianas, Porto Alegre, v. 14, n. 1, p. 93105 , jan./jun. 2011 .

\author{
Magalí Teresinha Longhi \\ Universidade Federal do Rio Grande do Sul \\ Patricia Alejandra Behar \\ Universidade Federal do Rio Grande do Sul \\ Magda Bercht
}

Universidade Federal do Rio Grande do Sul

\section{Introdução}

E ste artigo apresenta estudos e a avaliação de resultados obtidos na incorporação de um framework concebido para inferir estados de ânimo em ambiente virtual de aprendizagem (AVA). Trata-se de estudo realizado no âmbito de investigação mais ampla, empreendida pelo Núcleo de Tecnologias Aplicadas à Educação (NUTED) em conjunto com o Grupo de Computação Afetiva Aplicada à Educação (GCAE) da Universidade Federal do Rio Grande do Sul (UFRGS).

Nesse âmbito, a pesquisa tem por propósito examinar como a dimensão afetiva se expressa em contexto virtual e, em especial, a de como ela se manifesta no processo de aprendizagem ao longo das interações que acontecem em tais ambientes. Parte-se do pressuposto que a Educação a Distância não deve desconsiderar as relações afetivas. Para tanto, faz-se necessário criar ferramentas tecnológicas de modo a dotar novas 
funcionalidades em AVA, capazes de promover práticas pedagógicas mais sensíveis ao novo paradigma da Educação.

No que tange especificamente ao presente estudo, tem-se por hipótese ser possível reconhecer o(s) estado(s) de ânimo de um aluno em AVA por meio de um modelo computacional. Tal modelo é empregado com a finalidade de estabelecer relações entre a variável de estudo (estado de ânimo) e as variáveis independentes, quais sejam: traços de personalidade, fatores motivacionais e subjetividade afetiva identificada em textos disponibilizados em meio virtual. A plataforma utilizada para tanto é o AVA ROODA, da UFRGS.

Nesse contexto, este artigo apresenta a aplicação de uma rede bayesiana com vistas à inferência dos estados de ânimo de aluno. Tal investigação foi conduzida tendo por base disciplinas em nível de graduação, as quais contaram com o suporte do AVA ROODA.

Por tratar-se de uma pesquisa de cunho interdisciplinar (Psicologia, Educação e Informática), a próxima seção contempla a fundamentação teórica. Na seguinte, procede-se à compilação dos trabalhos da literatura relacionados aos métodos de inferência baseados em redes bayesianas (RB). Na seção 4, apresenta-se o modelo afetivo de aluno e a seção 5 , o mapeamento dos estados de ânimo. A seção 6 trata do ambiente de aplicação ROODA. Já a seção 7 mostra a máquina de inferência proposta e na 8,0 experimento e os resultados encontrados. Finalmente, são feitas algumas considerações a propósito do trabalho desenvolvido.

\section{Suporte teórico}

O papel da interação no processo de construção de conhecimento merece reconhecimento na psicogenética construtivista, a exemplo do que se verifica nas contribuições de Piaget (1973) e Vygotski (2001).

Inspirado em Piaget, Primo (2008) empreendeu um estudo sistêmico-relacional das interações sob a perspectiva tecnológica. $\mathrm{O}$ autor identificou duas modalidades de interação: a mútua e a reativa. A primeira se estabelece mediante relações interdependentes e processos de negociação, ao passo que a outra diz respeito a relações determinísticas do tipo ação-reação.

Em um AVA, as duas modalidades de interação não se verificam de forma exclusiva. Os sujeitos participantes não interagem apenas com a infraestrutura tecnológica - interface gráfica, ferramentas de comunicação síncrona/assíncrona e demais funcionalidades -, isto é, sob forma reativa. Há também, em tais ambientes, a formação de diversas relações que caracterizam a modalidade mútua, tais como as cognitivas, as afetivas, as simbólicas e as sócio-comportamentais (BEHAR, 2009).

Disso resulta que um AVA soma potencialidades para além de simples repositório de conteúdo, organização de uma disciplina/curso ou de contato entre os participantes. Vislumbra-se uma nova abordagem para AVA, cujas funcionalidades tecnológicas venham a representar fontes importantes para a inferência de aspectos afetivos.

Concorrendo nessa direção, a Computação Afetiva (PICARD, 1997) aglutina técnicas da Inteligência Artificial, Engenharia de Software e Engenharia da Computação, voltadas à afetividade e ao seu papel na experiência humana. No entanto, persistem dificuldades para modelar as emoções em sistemas computacionais, essencialmente em razão de três fatores, segundo Bercht (2007): à marcante influência do pensamento cartesiano, que vê a razão como contraposta à emoção; à indefinição dos termos associados à afetividade; e, por fim, de ordem computacional, ao uso de lógicas e formalismos voltados exclusivamente à representação do conhecimento.

A visão dicotômica entre cognição e afetividade perdurou até recentemente, desde que Platão distinguiu o corpo da "alma", estruturando-a na tríade cognição, emoção e volição (motivação). Após o advento dos computadores, os cientistas da cognição passaram a recorrer à nova tecnologia como instrumento para representar e simular processos mentais. O 
destaque na abordagem de processamento de informações (codificação, armazenagem e recuperação) resultou em que os pesquisadores das ciências cognitivas não considerassem adequadamente as relações entre a cognição e os aspectos afetivos (EYSENCK; KEANE, 1994). Embora Piaget (2005) e Vygotsky (2001) houvessem demonstrado interesse nessa relação, somente a partir da década de 80 a afetividade nas atividades cognitivas passou a ser enfatizada, tal como se verifica nas teorias de Zajonc (1980) e Lazarus (1982). Mais tarde, as pesquisas dos neurocientistas Damásio (1996) e Le Doux (2001) vieram a apresentar evidências significativas das relações entre cognição e afetividade.

A segunda dificuldade apontada por Bercht (2007) diz respeito à definição dos termos relacionados à afetividade, tais como emoção, estado de ânimo/humor, motivação, sentimento, traços de personalidade, etc. Esses termos são abordados por várias teorias psicológicas e, mesmo dentro delas, segundo diferentes orientações.

Por isso, as maneiras distintas de definir os inúmeros fenômenos afetivos suscitam dúvidas quanto à sua diferenciação. Scherer (2005) formulou critérios para diferenciá-los (importância do evento, tipo de appraisal, sincronização com os vários subsistemas orgânicos, impacto no comportamento, intensidade e duração). A partir de tais critérios é que, para fins do presente estudo, serão definidos os termos emoção, estados de ânimo e traços de personalidade. Sobretudo o segundo, particularmente relevante para os objetivos da investigação em curso.

A emoção, embora no senso comum seja tomada como sinônimo de afetividade e, muitas vezes, confundida com sentimento, consiste em um estado afetivo breve, de alta intensidade e de resposta sincronizada a um evento.

Uma emoção pode ser classificada tanto como primária (básica ou utilitária) quanto secundária (ou social). As primárias (medo, raiva, tristeza, alegria, surpresa, desprezo e aversão) servem para garantir a sobrevivência, e sob tal aspecto foram amplamente discutidas por Ekman (1999) em pesquisas realizadas a partir de diferentes culturas. Já as emoções secundárias (arrogância, preocupação, inquietação, mágoa, entusiasmo, espanto, repulsa, etc.) são adquiridas ou aprendidas a partir das primárias, à medida que se vivencie uma série de situações cotidianas e assim como seus desdobramentos.

Por sua vez, os estados de ânimo, uma classe de fenômenos afetivos e noção fundamental para o desenvolvimento desta investigação, representam um tipo de emoção de segundo plano (DAMÁSIO, 1996), de caráter ondulatório e difuso, de baixa intensidade, de longa duração. Esses estados podem ser desencadeados tanto por emoções primárias quanto secundárias (ROSENBERG, 1998).

Os traços de personalidade sinalizam padrões através dos quais o sujeito percebe a realidade, e sugerem como ele se relaciona. Normalmente, são determinados através de modelos caracterizados como fatores (ou dimensões), que denotam a especificidade de um indivíduo. Esses fatores são obtidos através da aplicação de testes psicométricos.

Assim, no entender de Rosenberg (1998), existe uma relação de composição entre os termos apresentados: as emoções são a unidade mais básica dos fenômenos afetivos; essas compõem os estados de ânimo que, em conjunto com as emoções, modelam os traços de personalidade.

A dificuldade na modelagem dos fenômenos afetivos em sistemas computacionais, terceiro fator de Bercht (2007), reside no uso de modelos criados sob o método científico cartesiano. Isso se verifica em função de os mecanismos cognitivos serem examinados de acordo com a visão reducionista (o mundo complexo deve ser dividido em partes mais simples). Esses modelos formais tratam do conhecimento pertinente tanto aos domínios completos e imutáveis quanto aos de raciocínio incerto. Também tratam da aprendizagem a partir das observações, da percepção do mundo e das ações a serem tomadas. Em todos esses aspectos, a questão da afetividade não é tratada.

Fellous, Armony e Le Doux (2002) afirmam que as técnicas de Inteligência 
Artificial podem ser empregadas para modelar os processos cognitivos (appraisals) dos fenômenos afetivos, ainda que cada um deles implique dificuldades teóricas. Assim, ao se modelar fenômenos afetivos, é preciso avaliar qual o modelo mais adequado para a representação de conhecimento, como também, para identificar as tecnologias que o suportam (GRATCH; MARSELLA, 2004). É certo, porém, que não há modelos perfeitos e capazes de identificar os estados afetivos. Por vezes, combinar modelos pode render melhores resultados do que se restringir a um único (PICARD, 1997).

\section{Trabalhos relacionados}

As redes bayesianas (RB) são largamente aplicadas em sistemas especialistas ou sistemas baseados em conhecimento de um determinado domínio (diagnóstico médico, por exemplo) (FLORES, 2002). Na última década, têm se destacado na representação da avaliação cognitiva dos aspectos afetivos, principalmente a partir das ações e de outras informações (por exemplo, expressão facial) de usuários em ambientes computacionais.

Investigações sobre o reconhecimento das emoções num ambiente virtual e a modelagem delas a partir de RB são apresentados em Ball e Breese(2000), Kshirsagar e Magnenat-Thalmann (2002), Conati e Maclaren (2009), Pantarolo (2008) e Boff (2008).

Notabilizam-se trabalhos que envolvem agentes personificados e conversacionais, que, a partir de informações sobre as expressões faciais inferem a emoção (BALL; BREESE, 2000), (KSHIRSAGAR; MAGNENATTHALMANN, 2002) e os estados de ânimo (KSHIRSAGAR; MAGNENAT-THALMANN, 2002) do usuário, de modo a gerar comportamentos adequados para com ele interagir.

Outros autores sugerem o uso de RB em agentes computacionais concebidos para inferir as emoções de alunos em jogos colaborativos (CONATI; MACLAREN, 2009), (PANTAROLO, 2008) e em sistemas tutores inteligentes (BOFF, 2008). O agente social proposto por Boff (2008) leva em consideração as características individuais do aluno, como desempenho, perfil social, aceitação (por parte de colega), estado afetivo e traços de personalidade, de forma a identificar seu perfil na proposição de grupos de trabalhos. O modelo de Conati (CONATI; MACLAREN, 2009) foi desenvolvido com o objetivo de avaliar os estados emocionais em um jogo educacional. Essa avaliação tem por suporte um monitoramento das interações do aluno a partir dos objetivos do jogo e preferências (a expressividade corporal também é evidência).

Abordagem semelhante foi adotada por Pantarolo (2008). O que distingue sua contribuição é, com base num jogo colaborativo, inferir as emoções do aluno em relação a si e aos demais colegas. O modelo afetivo considera as ações coordenadas e simétricas por parte dos alunos-jogadores em seu esforço de solucionar conjuntamente os desafios.

Sob forte influência dos trabalhos de Conati e Maclaren (2009), Pantarolo (2008) e Bof (2008), o modelo afetivo definido para esta investigação é suportado por uma rede semântica. O modelo tem por objetivo servir de meio para a avaliação cognitiva dos estados de ânimo em meio virtual.

\section{Modelo afetivo de aluno}

A proposta de modelo afetivo do aluno, representado pela rede semântica ilustrada na Figura 1, inspira-se no modelo de Scherer (2005).

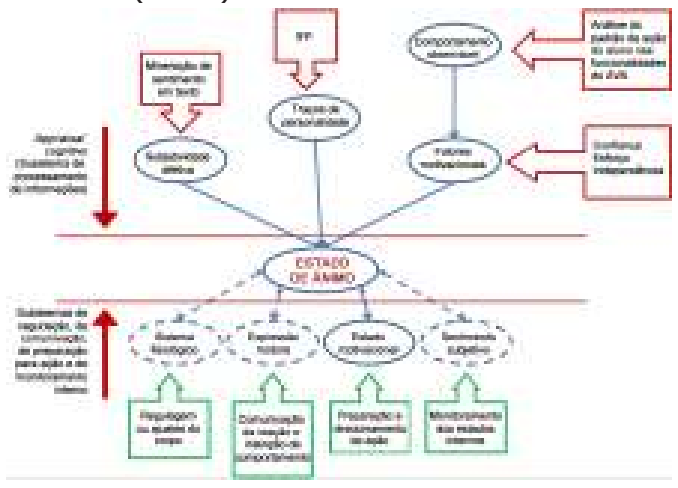

Figura 1 - Classe de variáveis e relações do modelo afetivo

Neste modelo, considera-se a subjetividade afetiva em texto como uma 
das variáveis explicativas do estado de ânimo do aluno. Ela envolve um julgamento unilateral (DORSCH; HÄCKER; STAPF, 2008), que se consolida à medida que o aluno registra suas preocupações, seus êxitos e motivações nos textos disponibilizados nas funcionalidades de comunicação síncrona e assíncrona do AVA.

A subjetividade afetiva é inferida através do framework AWM (Affective Word Mining), o qual tem por objetivo identificar e classificar as palavras de conotação afetiva presentes em um texto. Para esse efeito, o processo de mineração extrai os lexemas afetivos, que são submetidos à classificação. O processo de classificação consiste em verificar a qual posição da Roda dos Estados Afetivos (REA) cada lexema se insere (LONGHI; BEHAR; BERCHT, 2010) (o mapeamento dos estados de ânimo é apresentado na próxima seção).

O comportamento observável é entendido como um conjunto sistemático de ações adotadas pelo aluno no AVA. Dessa forma, os padrões verificados sinalizam o grau motivacional (Confiança, Esforço e Independência), considerado como um indicador dos estados de ânimo. Cada fator motivacional, inspirado no modelo de Bercht (2001), é identificado a partir de variáveis relacionadas ao comportamento observável: número de acessos (NA) a uma funcionalidade do ROODA, número de contribuições (NC) em fóruns, frequência (FP) e modo de participação (MP), pedidos ou prestação de ajuda (PA) e tempo de permanência (TP) na sessão. O grau motivacional é inferido pelo framework BFC (Behavioral Factor Calculation) descrito em (LONGHI; BEHAR; BERCHT; SIMONATO, 2010).

Os traços de personalidade constituem padrões através dos quais o sujeito percebe a realidade, e explicam como ele estabelece as conexões sociais. Normalmente, são determinados através de modelos caracterizados como fatores ou dimensões, os quais denotam a especificidade de um indivíduo. Essas dimensões são obtidas através da aplicação de testes psicométricos. $\mathrm{Na}$ pesquisa em curso, recorreu-se ao instrumento IFP (Inventário Fatorial da Personalidade) (PASQUALI;
AZEVEDO; GHESTI, 1997), com aplicação e análise por psicólogo. A escolha do IFP se justifica pelo fato de representar um instrumento adaptado à realidade brasileira, fidedigno e de natureza verbal mais consistente com os propósitos da pesquisa. Para a investigação, foram selecionadas nove dimensões: assistência, dominância, denegação, desempenho, agressão, ordem, persistência, mudança e autonomia.

As três variáveis (traços de personalidade, fatores motivacionais e subjetividade afetiva em texto) integram o subsistema de processamento de informações ou de appraisal (avaliação) cognitivo (SCHERER, 2005) para determinar o estado de ânimo correspondente. Os outros subsistemas do modelo de Scherer que tratam da regulação fisiológica, dramatização corporal, preparação para ação a ser tomada e de monitoramento dos componentes subjetivos não estão sendo contemplados neste trabalho.

\section{Mapeamento dos estados de ânimo}

Scherer e Tran (2001) descreveram o impacto de alguns fenômenos afetivos sobre o processo de aprendizagem, especialmente em organizações, de modo a indicar quais repercutiriam nos processos de tomada de decisão. Os autores identificaram quatro classes de emoções: condutivas, logrativas, resignativas e antagônicas.

As emoções, cuja principal função é modular as ações (DAVIDSON, 1994), podem evidenciar determinados estados de ânimo. O estado de ânimo exprime, muitas vezes, situações em que uma emoção, ou várias delas, permanecem subjacentes, atuando em background afetivo, colorindo nossa visão de mundo e modulando ou influenciando a cognição (DAVIDSON, 1994). Também pode ser inferido a partir de termos que contornam uma emoção (WATSON; TELLEGEN, 1985); por exemplo, a emoção alegria tem a ela relacionada os termos feliz, contente, encantado, etc. os quais remetem ao estado de ânimo Satisfação.

Assim, as emoções, classificadas em famílias afetivas, são posicionadas em um 
espaço de representação conforme apresentado na Figura 2. Esse espaço, denominado nesta investigação como Roda dos Estados Afetivos (REA), tem por origem o trabalho de Tran (2001).

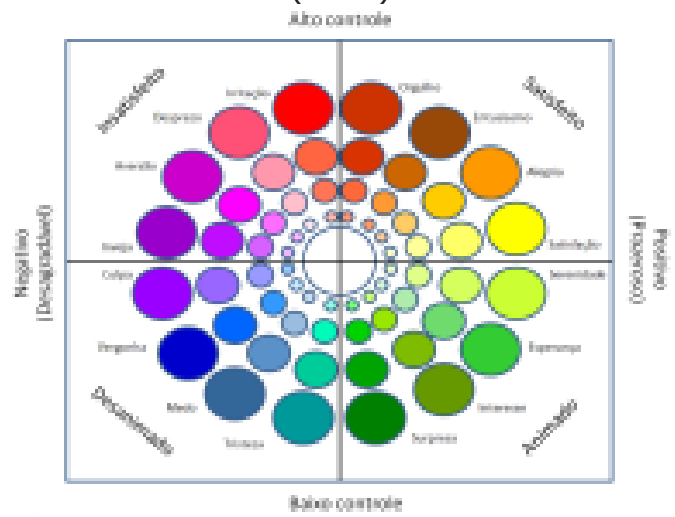

Figura 2 - Espaço de representação dos estados de ânimo, baseado em Tran (2001).

As famílias afetivas na REA constituem rótulos para um grupo de emoções. A posição das famílias em cada quadrante da REA tem sua fundamentação em justificativas empíricas e em extenso estudo teórico empreendido por Scherer (2005) e Tran (2001).

Neste trabalho, são consideradas duas classes de estados de ânimo: animação e satisfação. Cada classe, por sua vez, é dividida em duas subclasses a partir da valência positiva e negativa: animado, desanimado, satisfeito e insatisfeito.

\subsection{Animação}

O termo animação (do latim "anima" ou alma), no sentido figurado, designa a participação do subjetivo nos atos de percepção, representação e pensamento (DORSCH; HÄCKER; STAPF, 2008) sobre algo ou alguém. É o estado de ânimo que movimenta (ou não) em direção aos objetivos perseguidos. Pode ser identificada nos sentidos positivo e negativo.

No contexto educacional, ser ou estar animado evidencia que o aluno, de algum modo, demonstra surpresa, interesse, esperança e/ou serenidade para enfrentar os desafios da aprendizagem, o que 0 impele a colaborar e a cooperar.
Essas famílias afetivas (surpresa, interesse, esperança e serenidade) estão associadas à valência positiva e a baixo controle sobre os eventos causadores do estado afetivo, tanto quanto em relação a seus desdobramentos. Isto é, ao ser apresentado o conteúdo, o aluno revela disposição de confiança, ainda que detenha pouco controle sobre as situações de aprendizagem. Diz-se, nesse caso, que o estado de ânimo é orientado ao futuro. É composto por emoções condutivas, aquelas que imbuem o aluno de ânimo positivo para explorar, desenvolver e continuar o aprendizado.

É possível, no entanto, que tais emoções condutivas assumam conotação negativa: estar tranquilo demais pode induzi-lo à desistência; estar muito esperançoso pode levá-lo ao descompromisso e a praticar ações inapropriadas; estar demasiado interessado pode dispersá-lo; estar exageradamente surpreso pode originar ideias confusas ou deixá-lo paralisado, inerte ou ficar indiferente à aprendizagem.

O estado de ânimo desanimado sugere que o aluno, por algum meio, demonstra (ou reprime a manifestação de) tristeza, medo, vergonha e/ou culpa por não conseguir acompanhar o conteúdo.

Essas famílias afetivas caracterizam-se por valência negativa, baixo controle sobre os eventos e suas possíveis consequências, bem como tendência à submissão ou à renúncia. Compõem-se de emoções resignativas, ou seja, aquelas que podem, no limite, conduzir o aluno à desistência.

Contudo, podem ter implicações positivas, no sentido de permitir um tempo de recuperação para repensar atitudes, readaptar-se às novas condições ou evitar problemas.

\subsection{Satisfação}

O termo satisfação denota o prazer advindo da realização do que se espera, do que se deseja. No sentido positivo, o estado de ânimo satisfeito indica que o aluno transparece, de algum modo, satisfação, alegria, entusiasmo e/ou orgulho pela tarefa cumprida. 
Estas famílias afetivas compreendem valência positiva e significativo controle sobre os eventos e seus desdobramentos, proporcionando melhoria da auto-estima e do bem-estar. São compostas por emoções logrativas, ou seja, aquelas que estabelecem alcance de um objetivo e celebração do sucesso. Quando tais emoções são extravasadas, pode haver implicações adversas. De fato, um aluno muito orgulhoso pode suscitar inveja e hostilidade (precisando, então, lidar com conflitos). Deve-se considerar que entusiasmo ou alegria demais podem redundar em declínio de produtividade; do mesmo modo que alta satisfação pode desencorajar a exploração de novas alternativas.

Por outro lado, para a inferência do estado de ânimo insatisfeito, os indicativos são o de o aluno expressar, ou tentar não transparecer, irritação, desprezo, aversão e/ou inveja. Essas famílias afetivas, a que se atribuem valência negativa e alto controle sobre os eventos e suas consequências, revelam, especialmente, agressividade. São compostas por emoções antagônicas, a partir das quais o aluno pode fomentar intenções de represália ou de vingança.

Por outro lado, podem ter implicações desejáveis, como a de manter o grupo unido para atingir os objetivos e a aptidão para se contrapor a injustiças ou para superar obstáculos. A inveja, no seu sentido positivo, provoca admiração pelos exemplos de colegas e professores, sugerindo que se deva seguir pelo mesmo caminho. A aversão pode indicar que está na hora de mudar posições, atitudes ou comportamentos. O desprezo contribui para repensar normas sociais; e um pouco de raiva aumenta a confiança em algumas situações, como a de reagir a agressões.

\section{ROODA: o ambiente virtual de aprendizagem}

O ROODA (Rede coOperativa De Aprendizagem), institucionalizado pela UFRGS em 2005, é um AVA desenvolvido com base em princípios construtivistas, tendo implícita a concepção epistemológica interacionista (PIAGET, 1993).

As funcionalidades disponíveis no ROODA podem ser agrupadas nas classes: Recursos Gerais, Acompanhamento de Atividades, Publicação de Materiais e Comunicação.

O grupo de funcionalidades que contém Recursos Gerais permite visualizar e alterar dados cadastrais, personalizar a interface, registrar compromissos na disciplina, verificar o histórico de acessos às funcionalidades e acessar o item Ajuda.

As funcionalidades de Acompanhamento de Atividades são responsáveis pela disponibilização dos conteúdos de aula e estudo, dos exercícios e da participação de enquetes. Já os recursos Publicação de Materiais permitem a divulgação do material pessoal e de grupo com possibilidade de limitar a visualização dos conteúdos publicados.

Por fim, as ferramentas de comunicação síncrona e assíncrona integram o grupo de funcionalidades de Comunicação. Essas possibilitam encontros virtuais e espaços de convivência, sustentando o movimento de negociações, discussões e coordenações durante a realização da disciplina.

A máquina de inferência dos estados de ânimo é acoplada ao AVA ROODA através da funcionalidade ROODAafeto, desenvolvido pela equipe do NUTED/UFRGS. A nova funcionalidade integra a classe Recursos Gerais do AVA ROODA.

\section{Raciocínio probabilístico}

A tecnologia de rede bayesiana (RB) é a abstração computacional escolhida para apropriar a rede semântica descrita na seção 3. Tal escolha se deve ao fato de representar uma tecnologia adequada por considerar os aspectos de incerteza inerentes à dimensão afetiva. E, também, por tratar os aspectos dinâmicos dessa dimensão. Dessa forma, aplica-se o modelo afetivo de aluno sobre uma RB de forma a se obter inferências estatísticas, tendo em conta as probabilidades associada aos eventos observados.

Uma RB é um tipo de rede semântica representada por um grafo orientado acíclico, em que cada nodo possui 
informações de probabilidade (RUSSELL; NORVING, 2004). Os nodos representam as variáveis aleatórias (discretas ou contínuas) do problema com as medidas de incerteza associadas. As ligações entre os nodos são feitas por arcos que definem os vínculos. Os arcos identificam a precedência lógica ou influência causal entre as variáveis conectadas. Essa precedência, ou influência, determina a distribuição da probabilidade condicional, ou seja, é realizada uma quantificação do efeito dos nodos pais sobre os filhos.

A RB pode ser analisada sob duas perspectivas: qualitativa, pois o modelo gráfico representa a dependência entre os nodos; e quantitativa, por meio de tabelas de probabilidades condicionais (TPC).

Assim, os motivos que justificam a opção por uma RB neste trabalho são: 1) a RB permite expressar as assertivas de independência de forma visual e, por isso, pode-se ter uma percepção semântica do problema; 2) a RB é apropriada para representar e raciocinar com a incerteza, com probabilidades e imprecisão, características importantes que envolvem o tratamento dos aspectos afetivos; 3) a RB representa e armazena uma distribuição conjunta de forma reduzida, explorando a esparsidade do relacionamento entre as variáveis; e 4) a RB torna o processo de inferência eficiente do ponto de vista computacional, embora a distribuição de probabilidade possa crescer exponencialmente.

A RB, desenhada no software NETICA $v$. 4.16 e apresentada em duas partes na Figura 3, representa as relações das variáveis visualizadas na Figura 1. A variável Predominância-FP serve de elo entre as duas redes. Uma vez especificada a topologia da rede, foram definidas as TPCs de cada nodo.

As variáveis (ou nodos) independentes possuem valores de probabilidade a priori (ou incondicional), que indicam a crença sobre determinada proposição sem levar em conta outra informação qualquer. Assim, as probabilidades a priori estabelecidas para os nove traços de personalidade (ordem, mudança, persistência, autonomia, assistência, desempenho, dominância, agressão e denegação), os três fatores motivacionais (confiança, esforço e independência) e a subjetividade em texto é de $20 \%$.

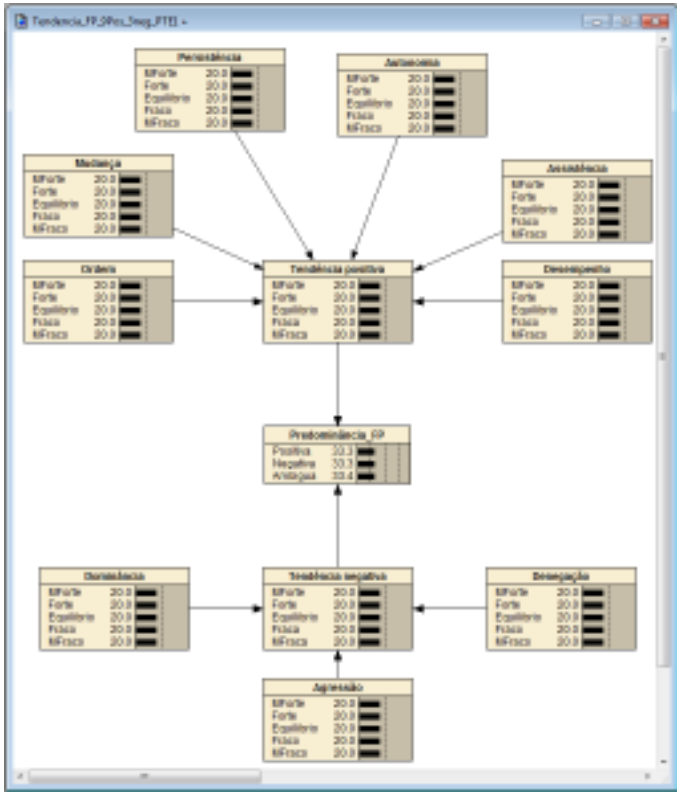

(a) Primeira parte

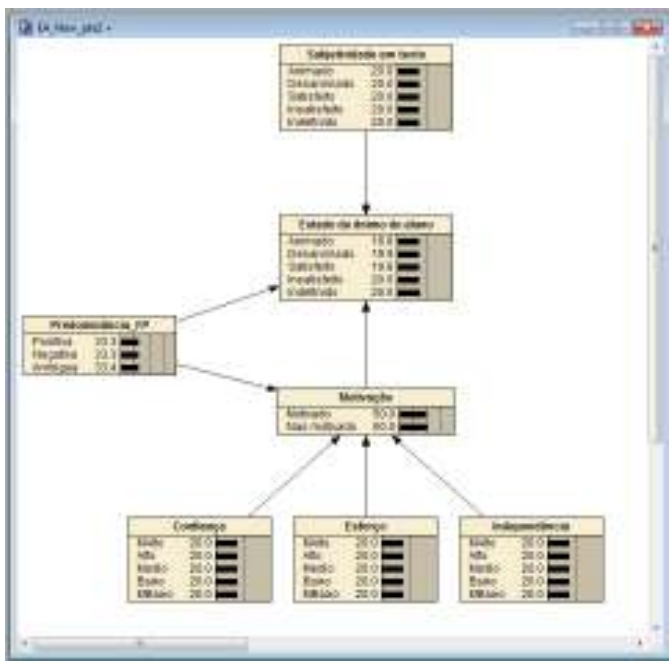

(b) Segunda Parte

Figura 3 - Rede bayesiana da pesquisa com as TPC a priori

Por outro lado, as variáveis dependentes possuem valores de probabilidade a posteriori (ou condicional). Isso significa que a probabilidade de um evento acontecer 
está condicionada à ocorrência de outros eventos. Nesse caso, as probabilidades condicionais para a tendência positiva e negativa dos traços de personalidade foram adquiridas com o auxílio de especialista e através da estimação das possíveis combinações. O mesmo foi estabelecido para as variáveis: motivação e estado de ânimo.

\section{Experimento e resultados}

A funcionalidade ROODAafeto, que congrega os frameworks AWM (minerador de subjetividade afetiva), BFC (cálculo dos fatores motivacionais) e a máquina de inferência, constituiu o recurso a partir do qual fez-se possível a coleta de dados. Os resultados, aqui apresentados, fazem parte de protótipo aplicado em 8 alunos de duas disciplinas do curso de graduação em Pedagogia da UFRGS. As informações sobre os traços de personalidade foram obtidas através da aplicação dos questionários IFP.

As disciplinas foram ministradas na modalidade presencial em que o AVA ROODA serviu de apoio para as discussões extrasala. As funcionalidades de comunicação utilizadas resumiram-se ao Fórum e ao Diário de Bordo. Os alunos casode-estudo (4 do sexo masculino e 4 do sexo feminino) concordaram em participar voluntariamente da pesquisa.

A coleta de dado transcorreu ao longo do primeiro semestre de 2010. No entanto, neste trabalho são apresentados os dados referentes às seis primeiras semanas de ocorrência das disciplinas. No período foi registrada a maior parte das contribuições no AVA ROODA.

A Tabela 1 apresenta os resultados produzidos pela primeira parte da RB, cuja topologia está ilustrada na Figura 3. As probabilidades em destaque informam a crença sobre a predominância dos traços de personalidade.

$\mathrm{Na}$ Tabela 2 encontram-se os resultados obtidos pelo framework AWM, cuja descrição pode ser encontrada em (LONGHI; BEHAR; BERCHT, 2010). O AWM define o quadrante (Ani - Animado, Sat - Satisfeito, Id Indefinido, encontrados na tabela) e a intensidade do estado afetivo nas mensagens postadas nas funcionalidades de comunicação. Observa-se que os alunos 192 e 561 não apresentaram textos com conotação afetiva e os 756 e 950 foram os que mais expuseram sua subjetividade nas mensagens postadas.

Tabela 1 - Predominância dos traços de personalidade

\begin{tabular}{|c|c|c|c|}
\hline \multirow{2}{*}{ Aluno } & \multicolumn{3}{|c|}{ Predominância } \\
\cline { 2 - 4 } & Positiva & Negativa & Ambígua \\
\hline 109 & 0,097 & $\mathbf{0 , 5 4 7}$ & 0,357 \\
\hline 192 & $\mathbf{0 , 4 7 1}$ & 0,163 & 0,366 \\
\hline 309 & 0,216 & $\mathbf{0 , 4 1 9}$ & 0,365 \\
\hline 441 & 0,425 & $\mathbf{0 , 4 2 6}$ & 0,150 \\
\hline 561 & 0,234 & 0,209 & $\mathbf{0 , 5 5 8}$ \\
\hline 729 & $\mathbf{0 , 7 3 9}$ & 0,074 & 0,187 \\
\hline 756 & 0,116 & $\mathbf{0 , 7 6 2}$ & 0,122 \\
\hline 950 & 0,123 & 0,318 & $\mathbf{0 , 5 5 9}$ \\
\hline
\end{tabular}

Tabela 2 - Estados de ânimo obtidos pelo framework AWM

\begin{tabular}{|c|c|c|c|c|c|c|c|c|}
\hline Semana & $\mathbf{1 0 9}$ & $\mathbf{1 9 2}$ & $\mathbf{3 0 9}$ & $\mathbf{4 4 1}$ & $\mathbf{5 6 1}$ & $\mathbf{7 2 9}$ & $\mathbf{7 5 6}$ & $\mathbf{9 5 0}$ \\
\hline 1 & Id & Id & Id & Id & Id & Id & Id & Id \\
\hline 2 & Id & Id & Id & Id & Id & Ani & Ani & Sat \\
\hline 3 & Id & Id & Id & Id & Id & Id & Ani & Sat \\
\hline 4 & Ani & Id & Ani & Id & Id & Id & Ani & Id \\
\hline 5 & Sat & Id & Sat & Ani & Id & Ani & Sat & Ani \\
\hline 6 & Id & Id & Id & Id & Id & Id & Id & Id \\
\hline
\end{tabular}

A Tabela 3 mostra os resultados encontrados pela máquina de inferência. Tais resultados foram obtidos através do algoritmo Counting-Learning suportado pelo software NETICA. Esse algoritmo implementa o modelo de aprendizagem de máquina conhecido como modelo de Bayes ingênuo ou Naïve Bayes.

Tabela 3 - Resultados da máquina de inferência

\begin{tabular}{|c|c|c|c|c|c|c|c|}
\hline \multirow{2}{*}{ Aluno } & \multicolumn{3}{|c|}{ Motivação } & \multicolumn{5}{|c|}{ Estado de ânimo } \\
\cline { 2 - 8 } & M & NM & A & D & S & Is & Id \\
\hline 109 & $\mathbf{0 , 5 2}$ & 0,48 & 0,18 & 0,03 & $\mathbf{0 , 5 2}$ & 0,05 & 0,23 \\
\hline 192 & $\mathbf{0 , 6 6}$ & 0,35 & 0,19 & 0,13 & 0,18 & 0,13 & $\mathbf{0 , 3 7}$ \\
\hline 309 & $\mathbf{0 , 5 6}$ & 0,44 & $\mathbf{0 , 5 9}$ & 0,03 & 0,17 & 0,30 & 0,18 \\
\hline 441 & $\mathbf{0 , 6 0}$ & 0,40 & $\mathbf{0 , 6 3}$ & 0,03 & 0,17 & 0,03 & 0,15 \\
\hline
\end{tabular}




\begin{tabular}{|l|l|l|l|l|l|l|l|}
\hline 561 & $\mathbf{0 , 5 5}$ & 0,45 & 0,18 & 0,14 & 0,16 & 0,14 & $\mathbf{0 , 3 9}$ \\
\hline 729 & $\mathbf{0 , 7 2}$ & 0,28 & $\mathbf{0 , 7 8}$ & 0,02 & 0,12 & 0,02 & 0,06 \\
\hline 756 & 0,40 & $\mathbf{0 , 6 0}$ & $\mathbf{0 , 4 6}$ & 0,04 & 0,21 & 0,04 & 0,25 \\
\hline 950 & 0,47 & $\mathbf{0 , 5 3}$ & 0,16 & 0,03 & $\mathbf{0 , 5 8}$ & 0,04 & 0,19 \\
\hline
\end{tabular}

O modelo Naïve Bayes é assim denominado porque considera todas as variáveis da rede como condicionalmente independentes (RUSSELL; NORVING, 2004). Isso assegura que, apesar da ideia simplista e "ingênua", esse modelo funciona muito bem para uma ampla variedade de aplicações (RUSSELL; NORVING, 2004).

A partir dos graus dos fatores motivacionais Confiança, Esforço e Independência, informados através do framework BFC, pôde-se verificar o nível de motivação do aluno nas seis semanas de estudo. O nível de motivação está apresentado nas colunas M (Motivado) e NM (Não Motivado) da Tabela 3.

A predominância nos traços de personalidade, a subjetividade afetiva em texto e o nível de motivação serviram de evidência para inferir a probabilidade dos estados de ânimo no final das semanas de análise.

Observa-se, na Tabela 3, que os valores obtidos para os alunos 192 e 561 definem uma estimativa maior para Indefinido, ainda que ambos estivessem moderadamente motivados.

O aluno 756, razoavelmente desmotivado em função da maneira como se comportou no ambiente, apresenta resultado consistente com o que está expresso na Tabela 2. Os traços de personalidade desse aluno confirmam a tendência negativa quanto à motivação (Tabela 1). Contudo, esse aluno demonstra um traço de personalidade conhecido como desejabilidade social (DS), conforme verificado na aplicação do questionário IFP.

A DS no instrumento IFP indica a tendência do participante da pesquisa em apresentar respostas consideradas mais aceitáveis, enfim, que sejam de aprovação social. O participante tende a dissimular sua opinião ou seu comportamento, por considerá-los socialmente não aceitos. Isso pode esclarecer por que a máquina de inferência decidiu por um estado de ânimo "mais favorável" à aprendizagem em relação a um aluno pouco motivado (em relação aos colegas).

O aluno 950 revela um comportamento semelhante ao 756, mas com baixa DS. Conclui-se, portanto, que o aluno mostrouse realmente entusiasmado com a disciplina.

Para os demais alunos, a máquina de inferência forneceu resultados conforme a expectativa.

\section{Considerações finais}

O reconhecimento dos estados afetivos envolve a captura e a análise dos sinais, os quais podem ser transformados em dados, com vista à construção do modelo afetivo do usuário. Através dele, o sistema computacional pode inferir as razões pelas quais o usuário experimentou determinado episódio afetivo. Para isso, faz-se necessário construir e atualizar dinamicamente o modelo afetivo-cognitivo do usuário, contemplando a incerteza dos dados obtidos no reconhecimento e a influência do cognitivo no afetivo, e vice-versa.

A abordagem dinâmica pressupõe: a) as incertezas advindas do tipo de modelo a ser empregado para representar a afetividade (modelo de Scherer); e b) eventuais falhas de compreensão das variáveis utilizadas, dada a provável precariedade dos "sinais" capturados. Parte-se, então, para o uso de raciocínio probabilístico implementado através de redes bayesianas.

O presente trabalho apresenta o estado da arte do processo de construção de uma máquina de inferência do estado de ânimo de aluno em AVAs. A máquina (e os frameworks associados) inserida na funcionalidade ROODAafeto, encontra-se em testes no ambiente de desenvolvimento do ROODA.

Para avaliar a possibilidade de construção, foi conduzido um experimento, cujos dados foram submetidos a um protótipo de rede implementada através do software NETICA v. 4.16. Na simulação, o aluno conta com uma representação cognitiva e afetiva limitada às características indispensáveis aos propósitos iniciais da pesquisa. Esse modelo tem o intuito de formalizar suas inter-relações, seja com o 
sistema, seja com os colegas. E, até mesmo, com os professores e/ou tutores.

Há a perspectiva de considerar uma amostra de estudo maior com o intuito de aumentar a confiabilidade dos resultados. Além dessa, vislumbra-se dois novos trabalhos. O primeiro, relacionado à incorporação de novas características ao modelo afetivo do aluno, como o estilo de aprendizagem, segundo Felder e Silverman (1998) e a atitude social, identificada através dos estudos em sociometria (SCHERMAN, 2002). O segundo caminho a ser trilhado refere-se à inclusão de novas variáveis no cálculo dos fatores motivacionais. Atualmente, apenas as variáveis associadas às ferramentas de comunicação do AVA ROODA são consideradas no cálculo dos padrões comportamentais.
O objetivo da pesquisa é o de construir um sistema computacional adaptativo, isto é, suficientemente dinâmico e flexível em face das características de cada aluno. Disso, eventualmente, pode resultar uma nova postura frente às interações que se formam no ambiente. De qualquer modo, importa reconhecer que a atividade de ensino, especialmente em meio virtual, constitui um processo complexo. Como tal, a par de diferentes potencialidades, deve-se propiciar discussões quanto a se as dificuldades encontradas decorrem de insuficiências tecnológicas ou pedagógicas, ou ainda, se resultam de motivos outros, como os de natureza individual.

\section{Agradecimentos}

Este estudo foi parcialmente financiado pelo CNPq (Processos No 472562/2008-8 e No 479132/2010-0), pela FAPERGS (Processo No 1017390/2010) e pela SEAD/UFRGS (Edital UFRGS EAD 12/2010).

\section{Referências}

BALL, G., and BREESE, J. "Relating Personality and Behavior: Posture and Gestures". In: PAIVA, A. M. (Ed.). Affective Interactions, LNAI 1814, p. 196-203. 2000.

BEHAR, P. A. Modelos Pedagógicos em Educação a Distância. Porto Alegre: Artmed. 2009. 316 p.

BERCHT, M. Computação Afetiva: vínculos com a psicologia e aplicações na educação. In: Psicologia \& Informática: produções do III PsicoInfo e II Jornada do NPDI. São Paulo: Conselho Regional de Psicologia de São Paulo. p.106-115. 2007

BERCHT, M. Em direção a agentes pedagógicos com dimensões afetivas. 2001. 152 f. Tese (Doutorado) Programa de Pós Graduação em Computação(PPGCC), Instituto de Informática, Universidade Federal do Rio Grande do Sul (UFRGS), 2001, Porto Alegre, BR-RS.

BOFF, E. Colaboração em ambientes inteligentes de aprendizagem mediada por um agente social probabilístico. 2008. Tese (Doutorado) - Programa de Pós-graduação em Ciência da Computação (PPGCC), Universidade Federal do Rio Grande do Sul (UFRGS), 2008, Porto Alegre, BR-RS.

CONATI, C., and MACLAREN, H. Empirically building and evaluating a probabilistic model of user affect. In: User Modeling and User-Adapted Interaction, v.19, n.3, p. 267-303, 2009.

DAMÁSIO, A. O Erro de Descartes: emoção, razão e o cérebro humano. VICENTE, D. e SEGURADO, G. (Trad.). São Paulo: Cia das Letras. 1996. 330 p.

DAVIDSON, R. J. On Emotion, Mood, and Related Affective Constructs. In: EKMAN, P., and DAVIDSON, R. J. The Nature of Emotion: Fundamental Questions. Oxford: Oxford University Press, p. 51-55. 1994.

DORSCH, F., HÄCKER, H., and STAPF, K. H. Dicionário de Psicologia Dorsch. Petrópolis, RJ: Vozes. 2008. 
EKMAN, P. Basic Emotions. In: DALGLEISH, T. and POWER, T. (Eds.). The Handbook of Cognition and Emotion. Sussex, U.K.: John Wiley \& Sons, Ltd. p. 45-60. 1999.

EYSENCK, M. W., and KEANE, M. T. Psicologia Cognitiva: um manual introdutório. GESSER, W. \& GESSER, M. H. F. (Trad.). Porto Alegre: Artes Médicas. 1994

FELDER, R., and SILVERMAN, L. K. Learning styles and teaching styles in Engineering education. Engineering Education. v.78, n.7, p. 674-681. 1998.

FELLOUS J. M., ARMONY J. L., and LE DOUX J. E. Emotional Circuits and Computational Neuroscience. In: ARBIB, M.A. (Ed.), The handbook of brain theory and neural networks, Second Edition. Cambridge, MA: The MIT Press. 2002.

FLORES, C. D. Fundamentos dos Sistemas Especialistas. In: BARONE, D. A. C. (Org.). Sociedades Artificiais: A Nova Fronteira da Inteligência nas Máquinas, Porto Alegre: Bookman (ArtMed), p. 127-154. 2002.

GRATCH, J., and MARSELLA, S. A Domain-independent framework for modeling emotion. Journal of Cognitive Systems Research, v.5, n.4, p. 269-306. 2004.

KSHIRSAGAR, S., and MAGNENAT-THALMANN, N. A Multilayer Personality Model. In: 2nd International Symposium on Smart Graphics. New York: ACM Press, p.107-115. 2002.

LAZARUS, R. S. Thoughts on the relations between emotion and cognition. American Psychologist, v.37, n.9, p. 1019-1010, Sep. 1982.

LE DOUX, J. O cérebro emocional: os misteriosos alicerces da vida emocional. SANTOS, T. B. (Trad.). Rio de Janeiro: Objetiva. 2001. 332 p.

LONGHI, M. T., BEHAR, P. A., and BERCHT, M. Em busca de palavras com conotação afetiva registradas em ambiente virtual de aprendizagem. In: Conferência IADIS Ibero-Americana WWW/Internet 2010, Algarve. Portugal. p. 43-50. 2010.

LONGHI, M. T., BEHAR, P. A., BERCHT, M. and SIMONATO, G. Os fatores motivacionais e os estados de ânimo em ambientes virtuais de aprendizagem. In: Congresso Iberoamericano de Informática Educativa. Santiago do Chile, Chile, Dez. 1-3, 2010. p. 551-558. 2010.

PANTAROLO, E. Modelagem probabilística de aspectos afetivos do aluno em um jogo educacional colaborativo. 2008. Tese (Doutorado) - Programa de Pós-graduação em Informática na Educação (PPGIE), Universidade Federal do Rio Grande do Sul (UFRGS), 2008, Porto Alegre, BR-RS.

PIAGET, J. Estudos Sociológicos. Rio de Janeiro: Forense. 1973. 231 p.

PIAGET, J. Inteligencia y afectividad. Buenos Aires: Aique. 2005. 116 p. Publicação original: Piaget, J. (1954) Les relations entre I'Intelligence et I'Affectivité dans le développement de l'enfant.

PICARD, R. W. Affective Computing. Cambridge: MIT Press. 1997. 292 p.

PRIMO, A. Interação mediada por computador: comunicação, cibercultura, cognição. Porto Alegre: Sulina. 2008. 240 p.

PASQUALI, L., AZEVEDO, M. M., and GHESTI, I. Inventário Fatorial de Personalidade: manual técnico e de aplicação. São Paulo: Casa do Psicólogo. 1997.

ROSENBERG, E.L. Levels of analysis and the organization of affect. Review of General Psychology, v. 2, n. 3, p. 247-270. 1998.

RUSSELL, S.J., and NORVING, P. Inteligência Artificial. Rio de Janeiro: Elsevier. 2004. 1021 p.

SCHERER, K. R., and TRAN, V. Effects of emotion on the process of Organization Learning. In: NONAKA I. (Ed.). Handbook of organizational learning and knowledge. Oxford, UK: Oxford University Press. p. 369392. 2001. 
SCHERER, K. R. What are emotions? And how can they be measured?. Social Science Information, v. 44, n.4, p. 695-729. 2005.

SCHERMAN, L. W. Sociometry in the classroom: how to do it. 2002. Disponível em <http://www.users.muohio.edu/shermalw/sociometryfiles/socio_introduction.htmlx>. Acesso em Dez/2010.

TRAN, V. The influence of emotions on decision-making processes in management teams. Faculté de Psychologie et des Sciences de I'Education. Université de Genève. Thèse No 323. 2004.

VYGOTSKI, L. S. A construção do pensamento e da linguagem. São Paulo: Martins Fontes. 2001. 496 p.

WATSON, D., and TELLEGEN, A. Toward a consensual structure of mood. Psychological Bulletin, v. 98, n.2, p.219-235. 1985.

ZAJONC, R. B. Feeling and thinking: preferences need no inferences. American Psychologist, v.35, n.2, p. 151-175, Feb. 1980.

Recebido em maio de 2011

Aprovado para publicação em junho de 2011

Magali Teresinha Longhi

Programa de Pós-Graduação em Informática da Educação - Universidade Federal do Rio Grande do Sul UFRGS, Porto Alegre - Brasil. E-mail: magali@cpd.ufrgs.br

\section{Patricia Alejandra Behar}

Programa de Pós-Graduação em Informática da Educação e Programa de Pós-Graduação Educação Universidade Federal do Rio Grande do Sul - UFRGS, Porto Alegre - Brasil. E-mail: pbehar@terra.com.br Magda Bercht

Programa de Pós-Graduação em Informática da Educação e Programa de Pós-Graduação em Ciência da Computação - Universidade Federal do Rio Grande do Sul - UFRGS, Porto Alegre - Brasil. E-mail: bercht@inf.ufrgs.br 